\title{
PELATIHAN PENGGUNAAN APLIKASI MICROSOFT POWERPOINT 2007 SEBAGAI ALAT PRESENTASI MAHASISWA FISIPOL UNIVERSITAS TIMOR
}

\author{
Nikolaus Uskono ${ }^{1)}$, Anita Lassa ${ }^{2)}$ \\ Ilmu Administrasi Negara, FISIPOL, Universitas Timor, Indonesia ${ }^{1), 2)}$ \\ Pos-el: anitalassa2@gmail.com²
}

\begin{abstract}
Dikirim: 22, 07, 2020
Direvisi: $12,08,2020$

Diterbitkan: 31, 08, 2020

Abstrak

Tujuan dari kegiatan pengabdian pada masyarakat ini adalah memberikan pelatihan penggunaan aplikasi Microsoft PowerPoint 2007 sebagai alat presentasi bagi mahasiswa.Kegiatan pengabdian ini dilaksanakan di Fakultas Ilmu Sosial dan Ilmu Politik Universitas Timor.Yang menjadi sasaran kegiatan adalah mahasiswa semester VI sebanyak 40 orang. Kegiatan pengabdian pada masyarakat dilakukan dengan menggunakan metode ceramah, metode demonstrasi, metode praktik, dan metode diskusi. Hasil yang dicapai dari kegiatan ini adalah mahasiswa Fakultas Ilmu Sosial dan Ilmu Politik Universitas Timor mampu menggunakan aplikasi Microsoft PowerPoint 2007 untuk membuat bahan presentasi.
\end{abstract}

Kata Kunci: Alat Presentasi, Ms PowerPoint 2007, Mahasiswa, Pelatihan

\section{Abstract}

The aims of this community service activity is to providetraining in using Microsoft PowerPoint 2007 applications for students as presentation tools. This service activity was carried out in the Faculty Of Social and Political Sciences, University of Timor. The 40 students of VI semester will become the target of this activity. The service was conducting by using lecturing method, demonstration method, practice method, and discussion method. The achievement result of this activity is the student of the Faculty of Social and Political Sciences of the University of Timor which having ability to use the Microsoft PowerPoint 2007 application to make presentation materials.

Keywords: Presentation Tools, Ms PowerPoint 2007, Students, Training.

\section{PENDAHULUAN}

Fakultas Ilmu Sosial dan Ilmu Politik (FISIPOL) terletak di Jalan KM. 09 Kelurahan Sasi Kecamatan Kota Kefamenanu Kabupaten Timor Tengah Utara.FISIPOL merupakan satu dari 4 fakultas yang berada di wilayah perbatatasan antara Negara Kesatuan Republik Indonesia (NKRI) dengan Republic Democratic Timor Leste RDTL.Hal ini menyebabkan mahasiswa FISIPOL sebagai salah satu civitas akademika memiliki peran penting dalam menopang kemajuan Negara Kesatuan Republik Indonesia dari wilayah perbatasan. Mengingat peran mahasiswa sangat penting maka mahasiswa dituntut untuk terus meningkatkan pengetahuan dan keterampilan. Dengan meningkatkan dan mengembangkan kemampuan dan keterampilan maka mahasiswa akan mampu menghadapi persaingan dalam waktu studi maupun menghadapi persaingan dunia kerja dimasa depan. Mahasiswa yang memiliki kemampuan dan keterampilan akan mampu meningkatkan daya saing bangsa Indonesia dengan bangsa lain. Hal ini dikarenakan tingkat persaingan sumber daya manusia 
di pasar kerja nasional maupun internasional terus mengalami peningkatan sejalan dengan peningkatan pemanfaatan ilmu pengetahuan dan teknologi pada berbagai bidang kerja.

Salah satu kemampuan dan keterampilan yang perlu dikuasai oleh mahasiswa FISIPOL dalam bidang teknologi khususnya penguasaan komputer.Penguasaan komputer tidak terlepas dari kemampuan untuk mengoperasikan aplikasi-aplikasi dasar yang tersedia dalam komputer. Salah satu aplikasi dasar komputer adalah Microsoft Office.Aplikasi ini membantu memudahkan pekerjaan kantor seperti pengetikan laporan, pembuatan laporan keuangan, pemaparan presentasi, dan lain-lain. Microsoft Office memiliki beberapa aplikasi yang sangat umum dipakai dan memiliki fungsi yang berbeda. Aplikasi tersebut diantaranya Mirosoft Word (pengolah kata) berfungsi untuk membuat surat, tabel, laporan, dan lain-lain; Microsoft Excel (aplikasi lembar kerja spreadsheet) berfungsi untuk mengolah data berupa angka dan grafik dalam menyusun laporan keuangan; dan Microsoft PowerPoint (Pengolah Presentasi) berfungsi membuat bahan presentasi yang menarik karena memiliki fitur animasi (Matondang, Sarumaha \& Juliana. 2016: 5-8). Mengingat pentingnya fungsi ketiga aplikasi Microsoft Office maka mahasiswa FISIPOL dituntut untuk mampu menggunakan aplikasi tersebut. Salah satu aplikasi yang wajib dikuasai adalah Microsoft Office PowerPoint. Hal ini mendesak karena setiap mahasiswa yang berada dalam lingkup Universitas Timor (UNIMOR) termasuk mahasiswa FISIPOL diwajibkan menggunakan alat presentasi ketika menyajikan proposal penelitian dan hasil penelitian.

Dengan mewajibkan mahasiswa untuk menggunakan alat presentasi dalam menyajikan bahan presentasi merupakan salah satu upaya UNIMOR untuk terus mendorong terjadinya transfer inovasi dan teknologi kepada masyarakat yang berguna bagi pembangunan ekonomi bangsa Indonesia dan mengembangkan penelitian yang bermanfaat bagi pertumbuhan pengetahuan dan wawasan bangsa di dunia (LPPM UNIMOR, 2016: 3). Sebelum pihak universitas mewajibkan seluruh mahasiswa menggunakan alat presentasi dalam menyajikan bahan presentasi, FISIPOL telah membekali mahasiswa dengan menjadikan aplikasi komputer sebagai salah satu mata kuliah wajib untuk diprogram pada tahun 2017. Karena merupakan mata kuliah yang baru dimasukkan ke dalam kurikulum tahun pada 2017 maka sebagian besar mahasiswa FISIPPOL belum memprogram mata kuliah tersebut. Kondisi ini berdampak belum terakomodirnya kebutuhan mahasiswa dalam hal pengenalan dan kemampuan menggunakan aplikasi Microsoft PowerPoint untuk membuat bahan presentasi. Berdasarkan pengamatan yang dilakukan diperoleh informasi bahwa sebagian besar mahasiswa FISIPOL menyajikan hasil diskusi tanpa menggunakan slide powerpoint. Mahasiswa hanya membacakan hasil diskusi yang dicetak dalam bentuk Microsoft Word.

Oleh karena itu, diperlukan alternatif kegiatan untuk dapat mengakomodir kebutuhan mahasiswa FISIPOL yaitu dapat membuat bahan presentasi menggunakan Ms. PowerPoint. Sehingga alternatif kegiatan yang ditawarkan adalah dengan memberikan pelatihan penggunaan aplikasi Microsoft PowerPoint versi 2007 kepada mahasiswa FISIPOL UNIMOR. Selain karena menjadi kebutuhan mahasiswa, pelatihan ini diberikan karena menimbang letak geografis UNIMOR yang berada di batas negara maka mahasiswa perlu memiliki pengetahuan dan keterampilan dalam bidang teknologi komputer agar mampu 
menghadapi perubahan dan persaingan secara nasional maupun international. Melalui pelatihan ini dapat meningkatkan kemampuan dan keterampilan mahasiswa FISIPOL UNIMOR dalam menggunakan aplikasi Ms PowerPoint sebagai alat bantu presentasi dan juga akan berguna ketika mahasiswa memasuki dunia kerja.

\section{METODE}

Kegiatan pengabdian kepada masyarakat dilaksanakan di Aula FISIPOL Universitas Timor selama 5 hari dari tanggal 9 Juli sampai dengan 13 Juli 2018. Metode pelaksanaan kegiatan yang digunakan dalam pelatihan penggunaan aplikasi Ms Powerpoint 2007 adalah metode ceramah untuk menjelaskan teori dan pengetahuan umum tentang aplikasi yang digunakan untuk membuat bahan presentasi menggunakan Ms PowerPoint 2007; metode metode demonstrasi untuk memperagakan urutan dan cara menggunakan menu dan toolbar aplikasi Ms PowerPoint 2007 dalam membuat bahan presentasi; metode praktik digunakan untuk mengetahui kemampuan mahasiswa setelah diberikan penjelasan mengenai cara penggunaan aplikasi Ms PowerPoint 2007 ketika membuat bahan presentasi. Peserta mempraktikan topik-topik materi yang dijelaskan; dan metode diskusi digunakan untuk memberikan kesempatan kepada peserta pelatihan bertukar pikiran dengan pengabdi dan peserta lainnya tentang kendala yang dialami ketika menggunakan Ms PowerPoint 2007.

\section{HASIL DAN PEMBAHASAN}

Yang menjadi fokus dari pelatihan ini adalah mahasiswa mampu menggunakan aplikasi Microsoft PowerPoint versi 2007 untuk pembuatan slide presentasi. Hal ini dikarenakan aplikasi Microsoft PowerPoint versi 2007 yang tersedia pada laptop yang dimiliki peserta.Kegiatan ini diawali dengan pengenalan fitur-fitur yang terdapat dalam $M s$ PowerPoint 2007 dan fungsinya. Setelah mengenal fitur-fitur dalam aplikasi Ms. PowerPoint 2007, peserta kegiatan diberikan penjelasan terkait cara menggunakan aplikasi tersebut dengan topik-topik berikut: mengaktifkan/membuka aplikasi, menutup aplikasi, membuat file baru dalam aplikasi, menyimpan dan membuka file, serta mencetak slide, note page, dan handout.

Setelah kegiatan pelatihan penggunaan aplikasi Ms PowerPoint 2007 alat presentasi bagi mahasiswa FISIPOL UNIMOR berakhir, maka kegiatan pengabdian yang diberikan sesuai dengan kebutuhan peserta; kegiatan ini juga memiliki dampak panjang karena memberikan bekal kemampuan dan keterampilan terkait pemanfaatan teknologi komputer; materi pelatihan yang diberikan bersifat praktis sehingga pelatihan yang diberikan mudah dikuasai oleh peserta meskipun terdapat beberapa peserta yang memiliki perbedaan dalam hal kecepatan dalam menguasai materi pelatihan, perlu adanya latihan yang berulang-ulang agar semakin terampil menggunakan aplikasi Ms PowerPoint 2007 dan aplikasi ini harus digunakan secara terus menerus agar materi pelatihan yang diperoleh tetap diingatkan dan dimanfaatkan.

Selama kegiatan berlangsung, peserta kegiatan diberikan latihan-latihan ketika satu topik selesai dibahas, sehingga mahasiswa yang mengalami kesulitan pada topik-topik tertentu didampingi secara intens dan tuntas sebelum topik selanjutnya dijelaskan. Dalam kegiatan ini ditemukan beberapa kendala diantaranya sebanyak enam peserta menggunakan aplikasi Ms PowerPoint versi 2010 sehingga ada perbedaan teknis penggunaan $M s$ 
PowerPoint 2010 dengan Ms PowerPoint 2007. Namun hal ini dapat diatasi dengan memberikan penjelasan teknis terkait penggunaan aplikasi Ms PowerPoint 2010 khusus untuk peserta yang menggunakan aplikasi versi 2010. Penyediaan modul pelatihan tentang dasar-dasar Ms. Office Power Point, tool-tool dalam Ms. Power Point dan cara pemanfaatan Ms. Power Point dalam pembuatan bahan presentasi sangat membantu peserta dalam memahami pembuatan bahan presentasi.

Berdasarkan hasi tes awal dan tes akhir terdapat peningkatan pengetahuan dan keterampilan 40 peserta untuk menggunakan Ms. Power Point dalam pembuatan bahan presentasi. Pelaksanaan kegiatan ini berjalan dengan lancar meskipun ada kendala dalam proses pelaksanaan namun karena minat dan semangat para peserta sangat tinggi ketika mengikuti kegiatan ini maka semua kendala dapat diatasi. Minat peserta ditunjukkan dengan kehadiran tepat waktu saat kegiatan,berlatih secara mandiri menggunakan Ms. Power Point di rumah, saling membantu diantara peserta kegiatan dalam mengerjakan tugas, menanyakan hal-hal yang kurang dipahami ketika berlatih di rumah menggunakan fasilitas grup Whatsapp yang dibentuk. Hasil kegiatan pengabdian ini sejalan dengan kegiatan pengabdian yang juga menggunakan Ms. Power Point (Dias K, Magdalena, Aditya, Setiawan, \& Christopher, M, 2019, Deda \& Disnawati, 2019) yang memberi dampak pada peningkatan kemampuan masyarakat dan guru kreatif dalam menggunakan MS. power point.

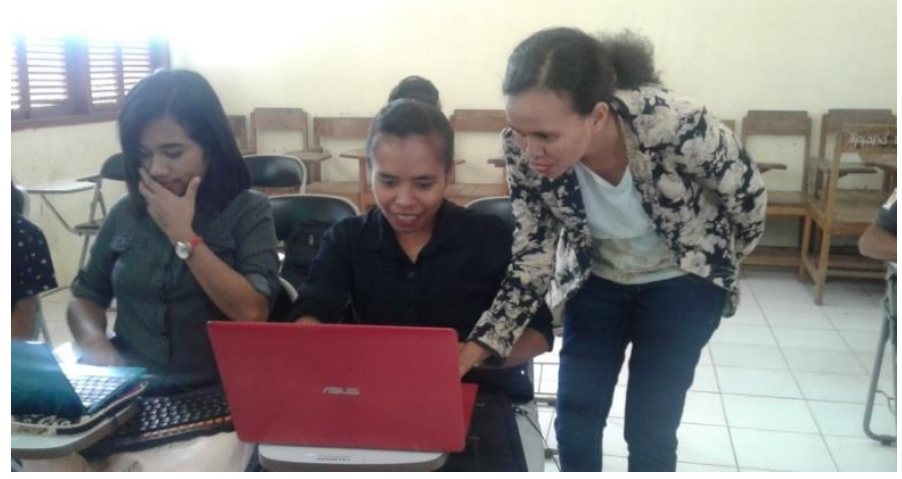

Gambar 1: Pendampingan Peserta

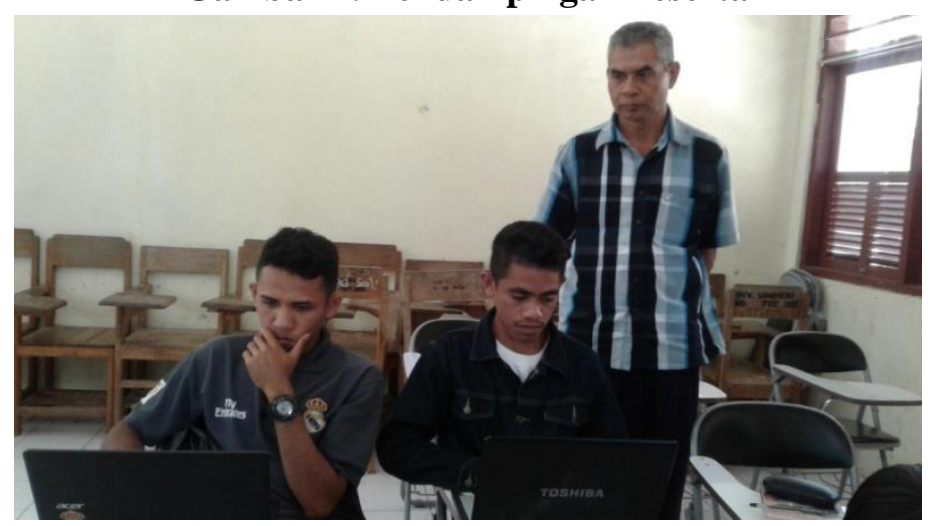

Gambar 2: Pendampingan Peserta 


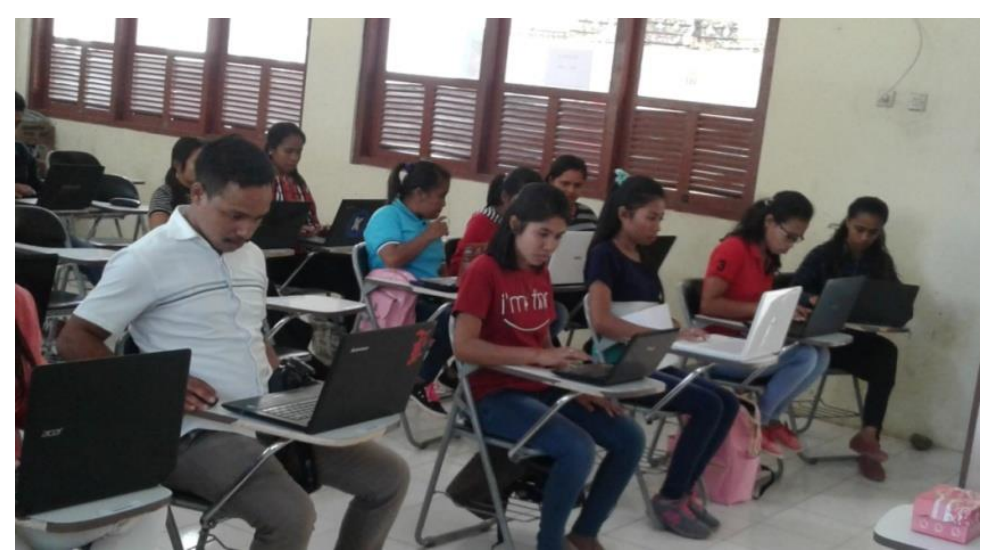

Gambar 3: Peserta Membuat Bahan Presentasi

\section{SIMPULAN}

Berdasarkan kegiatan pengabdian pada masyarakat yang telah dilaksanakan, disimpulkan bahwa mahasiswa semester VI FISIPOL UNIMOR yang berjumlah 40 orang telah mampu menggunakan aplikasi Microsoft PowerPoint 2007 untuk membuat bahan presentasi. Mahasiswa dibekali pengetahuan dan keterampilan dengan topik-topik terkait Microsoft PowerPoint 2007 yaitu cara mengaktifkan/membuka dan menutup aplikasi Ms. PowerPoint 2007; membuat file baru (membuat dan mengedit teks, menggunakan outline, membuat catatan, mengatur desain presentasi, mengatur format teks menggunakan dialog font dan menggunakan bullet and numbering, teknik penggunaan warna, mengubah warna background, menambahkan tabel, gambar, video, sound dan menggunakan efek dalam presentasi); menyimpan dan membuka file Ms. PowerPoint 2007; serta mencetak slide, note page, dan handout.

Dengan terselesaikannya kegiatan ini, terdapat beberapa saran yang dikemukakan diantaranya perlu diadakan kegiatan ekstrakurikuler terkait pemanfaatanfitur-fitur pada komputer agar kemampuan mahasiswa dalam pemanfaatan komputer sebagai bagian dari teknologi terus terasah meskipun pelatihan atau mata kuliah sistem informasi manajemen berakhir; mahasiswa yang telah mengikuti pelatihan dalam kegiatan pengabdian ini diberikan tanggung jawab menjadi tutor sebaya dengan sistem Multi-Level Marketing bagi mahasiswa FISIPOL yang belum memiliki kesempatan mengikuti pelatihan ini; dan mahasiswa FISIPOL harus memotivasi diri sendiri agar terus memperdalam pengetahuan dari berbagai sumber terkait fungsi-fungsi lanjutan dari aplikasi Ms PowerPoint selain versi 2007.

\section{UCAPAN TERIMA KASIH}

Kegiatan pengabdian masyarakat ini dapat diselesaikan sesuai dengan rencana karena dukungan dari berbagai pihak. Oleh karena itu, penulis menyampakan terima kasih kepada Lembaga Penelitian dan Pengabdian Pada Masyarakat (LPPM) UNIMOR yang telah memberikan dukungan dana untuk pelaksanaan kegiatan ini; Komite penilai yang telah mereview proposal pengabdian pada masyarakat yang diajukan penulis sehingga dinyatakan layak diterima dan didanai oleh pihak LPPM UNIMOR; Dekan FISIPOL UNIMOR yang telah memberikan fasilitas ruangan kepada penulis untuk melaksanakan kegiatan ini; dan para mahasiswa semester VI FISIPOL UNIMOR yang telah berpartisipasi dalam pelaksanaan kegiatan pengabdian ini; serta Pengelola Jurnal Bakti Cendana yang telah memberikan kesempatan kepada penulis untuk menerbitkan artikel hasil kegiatan pengabdian pada masyarakat. 


\section{DAFTAR PUSTAKA}

Cara Mudah Menggunakan Microsoft. 2013. [Online]. Avaible: http://mosof.blogspot.com. [Accessed: 20 Juni 2018]

Deda, Y.N. \& Disnawati, H. 2019. Workshop Media Animasi Untuk Meningkatkan Kreativitas Guru Di Kelurahan Kefamenanu Tengah. Ethos: Jurnal Penelitian dan Pengabdian kepada Masyarakat, 7(1):70-76.

Dias K, S.P. Magdalena, R. Aditya, F. Setiawan, A. Christopher M, G. 2019. Pelatihan Pembuatan Presentasi dengan Ms Office Power Point Bagi Masyarakat Desa Sampora. Available:http://Ejournal.Atmajaya.Ac.Id/Index.Php/Sabdamas/Article/View/1050/546. [Accessed: 11-Agustus-2020].

Fitur Ms. PowerPoint 2007. 2018. [Online]. Avaible:http://www.pptworkbench.com. [Accessed: 20 Juni 2018].

Lembaga Penelitian dan Pengabdian Masyarakat. 2016. Rencana Strategis Pengabdian Pada Masyarakat. Kefamenanu: Universitas Timor.

Matondang, E.S. Sarumaha, J.W \& Juliana 2016. [Online]. Available: http://jennysarumaha.blogspot.com/2016/04/makalah-tentang-microsoft-office.html. [Accessed: 26-Juni-2018]. 